\title{
The Versatility of Acellular Fetal Bovine Dermal Matrix for Head and Neck Surgical Reconstruction in Children
}

\author{
Jeremiah C. Tracy'1, William S. Kim¹, Andrew R. Scott1,2* \\ ${ }^{1}$ Department of Otolaryngology-Head and Neck Surgery, Tufts Medical Center, Boston, USA \\ ${ }^{2}$ Division of Pediatric Otolaryngology and Facial Plastic Surgery, Floating Hospital for Children, Boston, USA \\ Email: ${ }^{*}$ ascott@tuftsmedicalcenter.org
}

Received 23 July 2014; revised 22 August 2014; accepted 17 September 2014

Copyright (C 2014 by authors and Scientific Research Publishing Inc.

This work is licensed under the Creative Commons Attribution International License (CC BY). http://creativecommons.org/licenses/by/4.0/

cC) (i) Open Access

\section{Abstract}

Objectives: To describe the versatility of acellular fetal bovine dermal matrix as an alternative to human cadaveric allograft for head and neck reconstructive procedures in children. Study Design: Case series with chart review. Methods: A database of pediatric operative procedures was queried for the use of acellular fetal bovine dermal matrix over a 16-month period. Indications for reconstruction were assessed and initial parental and surgeon satisfaction with the product were noted. Results: During the time period of $3 / 2012$ and $7 / 2013$ a total of 8 reconstructive procedures were performed on pediatric patients using acellular fetal bovine dermal matrix. Indications for use varied and included open and transnasal endoscopic repair of encephaloceles and soft tissue reconstructions including lateral pharyngeal wall repair, cleft palate repair, and facial recontouring operations. Acellular fetal bovine dermal matrix had a subjectively increased ease of use as compared to the surgeon's prior experience with human cadaveric acellular dermis. Every parent vocalized a greater comfort level with the use of a bovine product over the alternative of human cadaveric tissue. The cost of acellular fetal bovine dermal matrix is slightly lower than the cost of human cadaveric acellular dermis. Conclusions: Acellular fetal bovine dermal matrix appears to be an acceptable alternative to human cadaveric acellular dermis for various forms of head and neck soft tissue reconstruction in children. Further prospective studies are warranted to assess for any differences in the long-term efficacy of this product as compared to other forms of allograft reconstruction.

\section{Keywords}

Acellular Fetal Bovine Dermal Matrix (SurgiMend), Human Cadaveric Acellular Dermal Allograft (AlloDerm), Skull Base, Cerebrospinal Fluid Leak Repair, Pediatric, Atrophic Scar, Parotidectomy

${ }^{*}$ Corresponding author.

How to cite this paper: Tracy, J.C., Kim, W.S. and Scott, A.R. (2014) The Versatility of Acellular Fetal Bovine Dermal Matrix for Head and Neck Surgical Reconstruction in Children. International Journal of Clinical Medicine, 5, $1119-1124$. 


\section{Defect, Parry Romberg, Cleft Palate}

\section{Introduction}

The field of pediatric head and neck reconstruction continues to evolve. There is a growing armamentarium of techniques and materials available to the reconstructive surgeon, with the introduction of injectable fillers and biological products continuing outpace research into the safety and efficacy of these modalities in children. Additionally, application of the endoscope has allowed for the transition from open to endoscopic approaches to pediatric skull base repair using techniques that rely on a variety of materials including tissue glues, allogeneic implants, autografts, and mucosal grafts or flaps [1]. Human cadaveric dermal matrices have found broad application in reconstructive head and neck surgery, including use in septoplasty, parotidectomy, and oral cavity reconstruction [2]-[5]. The use of human cadaveric acellular dermal allograft (AlloDerm, LifeCell, Bridgewater, NJ) has become standard practice in many forms of pediatric soft tissue and skull base repair [6]-[9]. In skull base reconstruction this product is generally used as an in-lay graft as part of a multilayered closure; many different nuances of application have been described [10]-[13]. The relative advantages of allograft reconstruction may include product availability, ease of endoscopic tissue manipulation, and avoidance of donor site morbidity (relative to autologous tissue).

Recently a new biological product, acellular fetal bovine dermal matrix (SurgiMend, TEI Biosciences, Waltham, MA), was approved by the Food and Drug Administration as a medical device. Acellular fetal bovine dermal matrix is comprised of tissue that has been terminally sterilized, with theoretical disease transmission risk that is favorable compared to human cadaveric dermis. This product has been applied in wound closure in both cosmetic and general surgery procedures in both adults and children [14] [15]. We recently presented three cases comprising our initial experience using this product for pediatric skull base reconstruction [16]. Within this present series we report on our growing experience using acellular fetal bovine dermal matrix for endoscopic and open pediatric head and neck reconstruction.

\section{Materials and Methods}

After institutional review board approval was obtained, a database of pediatric operative procedures was queried for the use of fetal bovine derived acellular dermal matrix over a 16-month period (3/2012 to 7/2013). Indications for soft tissue reconstruction were assessed and initial parental and surgeon satisfaction with the product were noted.

\section{Results}

Eight patients were identified. Indications for allograft reconstruction included congenital and post-traumatic encephalocele repair and head and neck soft tissue reconstructions (lateral pharyngeal wall repair, cleft palate repair, and facial recontouring procedures). Case descriptions and outcomes are summarized in Table 1.

Three patients had undergone anterior or lateral skull base reconstruction (Figure 1) and three additional cases involved the use of acellular fetal bovine dermal matrix to provide improved contouring of facial defects or scars. In these cases the dermal matrix was placed in the subdermal or subperiosteal plane to address depressed scar or atrophic dermis and soft tissue (Figure 2).

There was one case in which the matrix was used in an underlay fashion to prevent oronasal fistula formation in the context of a primary palatoplasty for closure of a wide cleft palate. The width of the cleft was wider than the width of the oral mucoperiosteal flaps in this case, preventing a proper multilayer closure along the lateral edges of the medially-advanced oral flaps. Additionally a small tear had occurred laterally during mobilization of the nasal mucoperiosteal flap on one side (Figure 3).

In the final case, the dermal matrix was used to repair a lateral pharyngeal wall defect, which could not be closed primarily due to excessive tension on the wound. The purpose of using a dermal matrix for repair in this case was to provide a scaffold for epithelial in growth while protecting the parapharygeal fat and carotid sheath from desiccation and gross contamination with oral flora.

Fetal bovine derived acellular dermal matrix had a subjectively increased ease of use in regards to tissue 
Table 1. A summary of pediatric patients included in this study.

\begin{tabular}{|c|c|c|c|c|}
\hline Subject & Age & Sex & Indication & Successful repair? \\
\hline 1 & $11 \mathrm{y}$ & $\mathrm{F}$ & $\begin{array}{l}\text { Transnasal endoscopic repair of traumatic sphenoid encephalocele } \\
\text { with cerebrospinal fluid leak. }\end{array}$ & Yes, no leak at 1 year. \\
\hline 2 & $13 \mathrm{y}$ & M & $\begin{array}{l}\text { Open repair of lateral skull base defect following resection and } \\
\text { subsequent radiation of temporal bone rhabdomyosarcoma. }\end{array}$ & Yes, 1 year. \\
\hline 3 & $17 \mathrm{y}$ & M & Transnasal endoscopic repair of frontoethmoid encephalocele. & Yes, no leak at 1 year. \\
\hline 4 & $1 \mathrm{y}$ & M & Closure of wide cleft palate. & Yes, no fistula at 2 years. \\
\hline 5 & $2 \mathrm{y}$ & M & Transoral repair of iatrogenic lateral pharyngeal wall defect. & Yes, complete healing by 3 months. \\
\hline 6 & $8 \mathrm{y}$ & M & Recontouring of depressed, paramandibular facial scar. & Yes, maintained symmetry at 3 years. \\
\hline 7 & $10 \mathrm{y}$ & M & $\begin{array}{l}\text { Recontouring of parotidectomy defect following excision of first } \\
\text { branchial cleft vestige. }\end{array}$ & Yes, maintained symmetry at 2 years. \\
\hline 8 & $10 \mathrm{y}$ & $\mathrm{F}$ & $\begin{array}{l}\text { Recontouring of forehead and brow for progressive hemifacial } \\
\text { atrophy (Parry Romberg syndrome). }\end{array}$ & $\begin{array}{l}\text { No, perceived resorption vs disease } \\
\text { progression at } 6 \text { months. }\end{array}$ \\
\hline
\end{tabular}



Figure 1. Repair of a parasellar skull base encephalocele via an endonasal endoscopic approach. Dermal matrix placement into a right anterosuperior sphenoid region defect (A) (subject 1). Note pliability of grafting material (B).

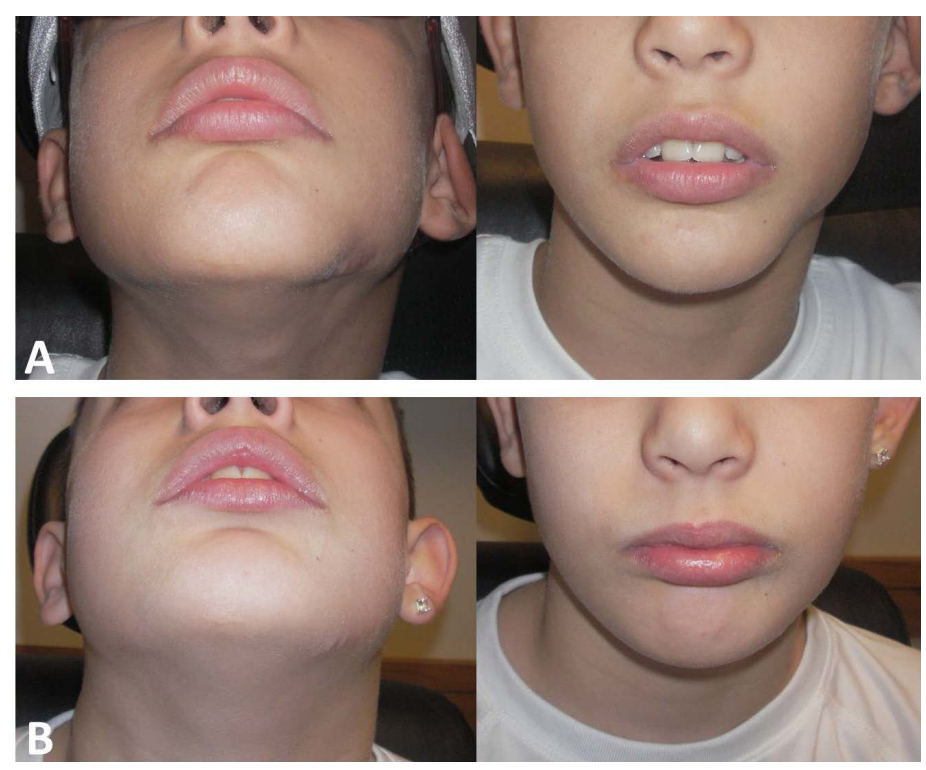

Figure 2. Facial recontouring of an atrophic and depressed paramandibular scar in subject 6. (A) Prior to reconstruction. (B) Following placement of acellular fetal bovine dermal matrix into a tight, subperiosteal pocket through a transoral incision. 

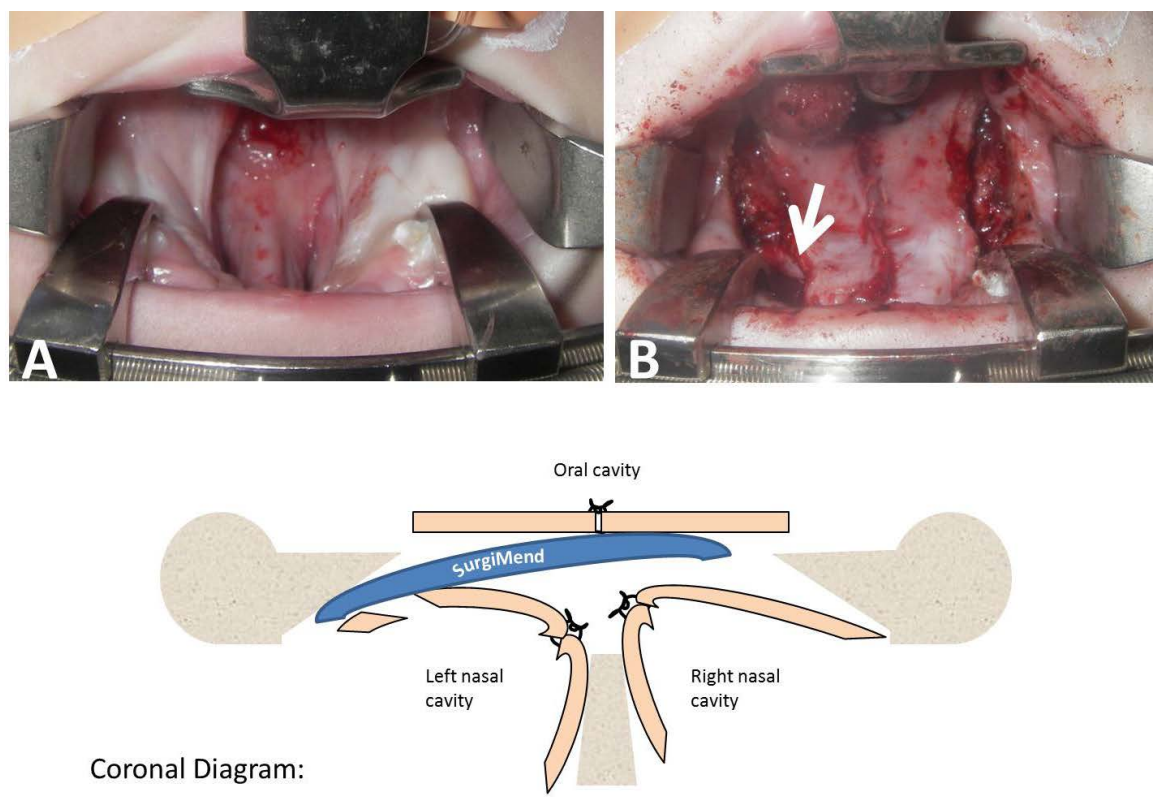

Figure 3. Reinforcement of a tenuous cleft palate repair in subject 4, using a sheet of acellular fetal bovine dermal matrix as an interposition graft. (A) Wide cleft of the secondary palate. (B) Intraoperative appearance immediately following repair. White arrow points to allograft. A coronal diagram depicts graft placement.

handling as compared to the surgeon's prior experience with human cadaveric acellular dermis. Additionally, every parent vocalized a greater comfort level with the use of a bovine product over the alternative of irradiated, human cadaveric tissue. Acellular fetal bovine dermal matrices are available in a wider variety of graft thicknesses when compared to available human cadaveric products that are currently available, and the cost of fetal bovine derived acellular dermal matrix is lower than human cadaveric products (Table 2).

\section{Discussion}

Human acellular dermal matrix has been accepted as a useful product in pediatric soft tissue reconstruction and the endoscopic repair of skull base defects [6]-[9]. There are several reasons why acellular fetal bovine dermal matrix may be superior to human cadaveric tissue for soft tissue and skull base reconstruction. First, acellular fetal bovine dermal matrix is more pliable than human cadaveric tissue and easier to work with in tight spaces (e.g. a tight tissue pocket or endoscopically). In addition to inherent tissue characteristics that make this allograft more pliable than other options, it is available in variable 1, 2, 3, or $4 \mathrm{~mm}$ thicknesses. These details can be important when performing surgery on children at various stages of development.

Second, acellular fetal bovine dermal matrix is available at a lower cost when compared to human tissue products. A recent review of dermal allografts found acellular fetal bovine dermal matrix to be one of the least costly products available, with an estimated cost of 23 dollars $/ \mathrm{cm}^{2}$ as compared to 28 - 35 dollars $/ \mathrm{cm}^{2}$ for human cadaveric dermal products [14] [15]. Finally, acellular fetal bovine dermal matrix is classified as a medical device rather than a tissue product. While cadaveric allografts are sterilized and irradiated to eradicate communicable disease, some patients (especially parents of infants and children) are uncomfortable with the use of a human tissue product from an anonymous donor. In our initial experience, parents are more comfortable with the concept of sterilized xenografts than implanted human cadaveric allografts.

Although there are no prior studies on the use of this product in pediatric head and neck or skull base reconstruction, it has been relatively well-studied in other fields. Acellular fetal bovine dermal matrix was first developed for use in pediatric inguinal hernia reconstruction [14]. Currently, the most well documented application of this product has been in breast reconstruction. Butterfield et al. recently published a review of over 400 cases performed with either acellular fetal bovine dermal matrix or human cadaveric dermal products. This study found a higher rate of postoperative seroma in the cases with human cadaveric dermal matrix, although statistical significance was not achieved [15]. 
Table 2. Approximate price per square centimeter of currently available acellular dermal matrices, adapted from Cheng et al. [14] "SurgiMend" is acellular fetal bovine dermal matrix whereas all other products listed are human cadaveric tissue.

\begin{tabular}{cc}
\hline Product name & Approximate price per $\mathrm{cm}^{2}$ \\
\hline AFBDM (SurgiMend) & $\$ 23$ \\
AlloDerm & $\$ 28$ \\
DermaMatrix & $\$ 28.51-\$ 31.94$ \\
FlexHD & $\$ 27.31-\$ 34.76$ \\
AlloMax & $\$ 32.38$ \\
DermACELL & $\$ 34$ \\
\hline
\end{tabular}

AFBDM: acellular fetal bovine dermal matrix.

\section{Conclusion}

Acellular fetal bovine dermal matrix (SurgiMend) may be a comparable material to human cadaveric acellular dermal matrices for pediatric head and neck and skull base reconstruction. Increased pliability, lower cost, and classification as a medical device rather than a tissue are potential advantages of this product, as compared with human cadaveric tissue. Further comparison studies are warranted.

\section{Acknowledgements}

The authors wish to acknowledge Dr. Jonathan Sillman and Dr. Mark Vecchiotti who performed the surgery for subject 2 in this series.

\section{Financial Disclosures}

None of the authors have an affiliation or financial interest in the makers of AlloDerm or SurgiMend. Andrew Scott, MD is a paid consultant for Advance Medical-expert medical second opinions.

\section{Conflict of Interest}

None.

\section{Source of Funding}

Interdepartmental funds.

\section{References}

[1] Banks, C.A., Palmer, J.N., Chiu, A.G., O’Malley Jr., B.W., Woodworth, B.A. and Kennedy, D.W. (2009) Endoscopic Closure of CSF Rhinorrhea: 193 Cases over 21 Years. Otolaryngology-Head and Neck Surgery, 140, 826-833. http://dx.doi.org/10.1016/j.otohns.2008.12.060

[2] Shridharani, S.M. and Tufaro, A.P. (2012) Systematic Review of Acellular Dermal Matrices in Head and Neck Reconstruction. Plastic and Reconstructive Surgery, 130, 35S-43S. http://dx.doi.org/10.1097/PRS.0b013e31825eff7a

[3] Kridel, R.W., Foda, H. and Lunde, K.C. (1998) Septal Perforation Repair with Acellular Human Dermal Allograft. Archives of Otolaryngology-Head and Neck Surgery, 124, 73-78. http://dx.doi.org/10.1001/archotol.124.1.73

[4] Sachsman, S.M. and Rice, D.H. (2007) Use of AlloDerm Implant to Improve Cosmesis after Parotidectomy. Ear, Nose Throat Journal, 86, 512-513.

[5] Girod, D.A., Sykes, K., Jorgensen, J., Tawfik, O. and Tsue, T. (2009) Acellular Dermis Compared to Skin Grafts in Oral Cavity Reconstruction. Laryngoscope, 119, 2141-2149. http://dx.doi.org/10.1002/lary.20548

[6] Munson, P.D. and Moore, E.J. (2010) Pediatric Endoscopic Skull Base Surgery. Current Opinion in Otolaryngology Head and Neck Surgery, 18, 571-576. http://dx.doi.org/10.1097/MOO.0b013e3283401fdc

[7] Achauer, B.M., VanderKam, V.M., Celikoz, B. and Jacobson, D.G. (1998) Augmentation of Facial Soft-Tissue Defects with AlloDerm Dermal Graft. Annals of Plastic Surgery, 41, 503-507. http://dx.doi.org/10.1097/00000637-199811000-00009 
[8] Aldekhayel, S.A., Sinno, H. and Gilardino, M.S. (2012) Acellular Dermal Matrix in Cleft Palate Repair: An EvidenceBased Review. Plastic and Reconstructive Surgery, 130, 177-182. http://dx.doi.org/10.1097/PRS.0b013e318254b2dc

[9] Shah, R.N., Surowitz, J.B., Patel, M.R., et al. (2009) Endoscopic Pedicled Nasoseptal Flap Reconstruction for Pediatric Skull Base Defects. Laryngoscope, 119, 1067-1075. http://dx.doi.org/10.1002/lary.20216

[10] Lorenz, R.R., Dean, R.L., Hurley, D.B., Chuang, J. and Citardi, M.J. (2003) Endoscopic Reconstruction of Anterior and Middle Cranial Fossa Defects Using Acellular Dermal Allograft. Laryngoscope, 113, 496-501. http://dx.doi.org/10.1097/00005537-200303000-00019

[11] Clark, D.W., Citardi, M.J. and Fakhri, S. (2010) Endoscopic Management of Skull Base Defects Associated with Persistent Pneumocephalus Following Previous Open Repair: A Preliminary Report. Otolaryngology-Head and Neck Surgery, 142, 820-826. http://dx.doi.org/10.1016/j.otohns.2009.12.041

[12] Hadad, G., Bassagasteguy, L., Carrau, R.L., et al. (2006) A Novel Reconstructive Technique after Endoscopic Expanded Endonasal Approaches: Vascular Pedicle Nasoseptal Flap. Laryngoscope, 116, 1882-1886. http://dx.doi.org/10.1097/01.mlg.0000234933.37779.e4

[13] Ismail, A.S., Costantino, P.D. and Sen, C. (2007) Transnasal Transsphenoidal Endoscopic Repair of CSF Leakage Using Multilayer Acellular Dermis. Skull Base, 17, 125-131. http://dx.doi.org/10.1055/s-2007-970556

[14] Cheng, A. and Saint-Cyr, M. (2012) Comparison of Different ADM Materials in Breast Surgery. Clinics in Plastic Surgery, 39, 167-175. http://dx.doi.org/10.1016/j.cps.2012.02.004

[15] Butterfield, J.L. (2013) 440 Consecutive Immediate, Implant-Based, Single-Surgeon Breast Reconstructions in 281 Patients: A Comparison of Early Outcomes and Costs between SurgiMend Fetal Bovine and AlloDerm Human Cadaveric Acellular Dermal Matrices. Plastic and Reconstructive Surgery, 131, 940-951. http://dx.doi.org/10.1097/PRS.0b013e3182865ab3

[16] Tracy, J.C., Sillman, J., Vecchiotti, M.A. and Scott, A.R. (2014) The Use of Acellular Fetal Bovine Derived Autograft for Pediatric Skull Base Reconstruction. Presented as a Poster Presentation at the 24th Annual North American Skull Base Society Meeting, San Diego, 14-16 February 2014. 
Scientific Research Publishing (SCIRP) is one of the largest Open Access journal publishers. It is currently publishing more than 200 open access, online, peer-reviewed journals covering a wide range of academic disciplines. SCIRP serves the worldwide academic communities and contributes to the progress and application of science with its publication.

Other selected journals from SCIRP are listed as below. Submit your manuscript to us via either submit@scirp.org or Online Submission Portal.
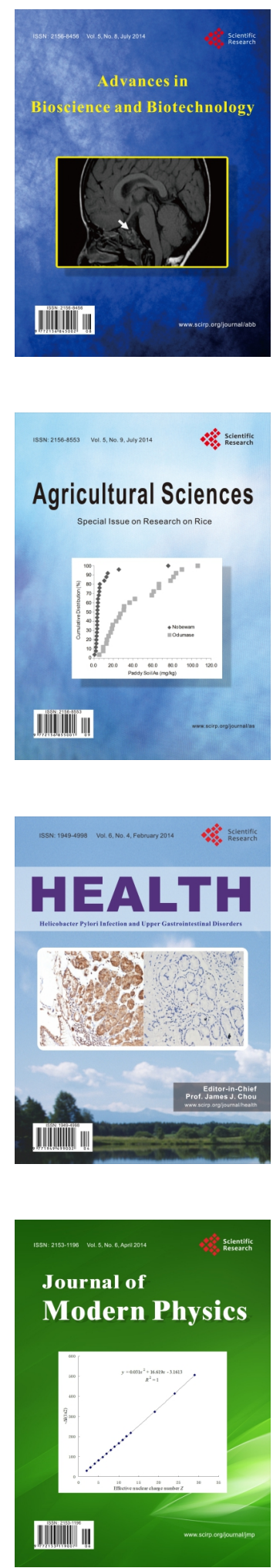
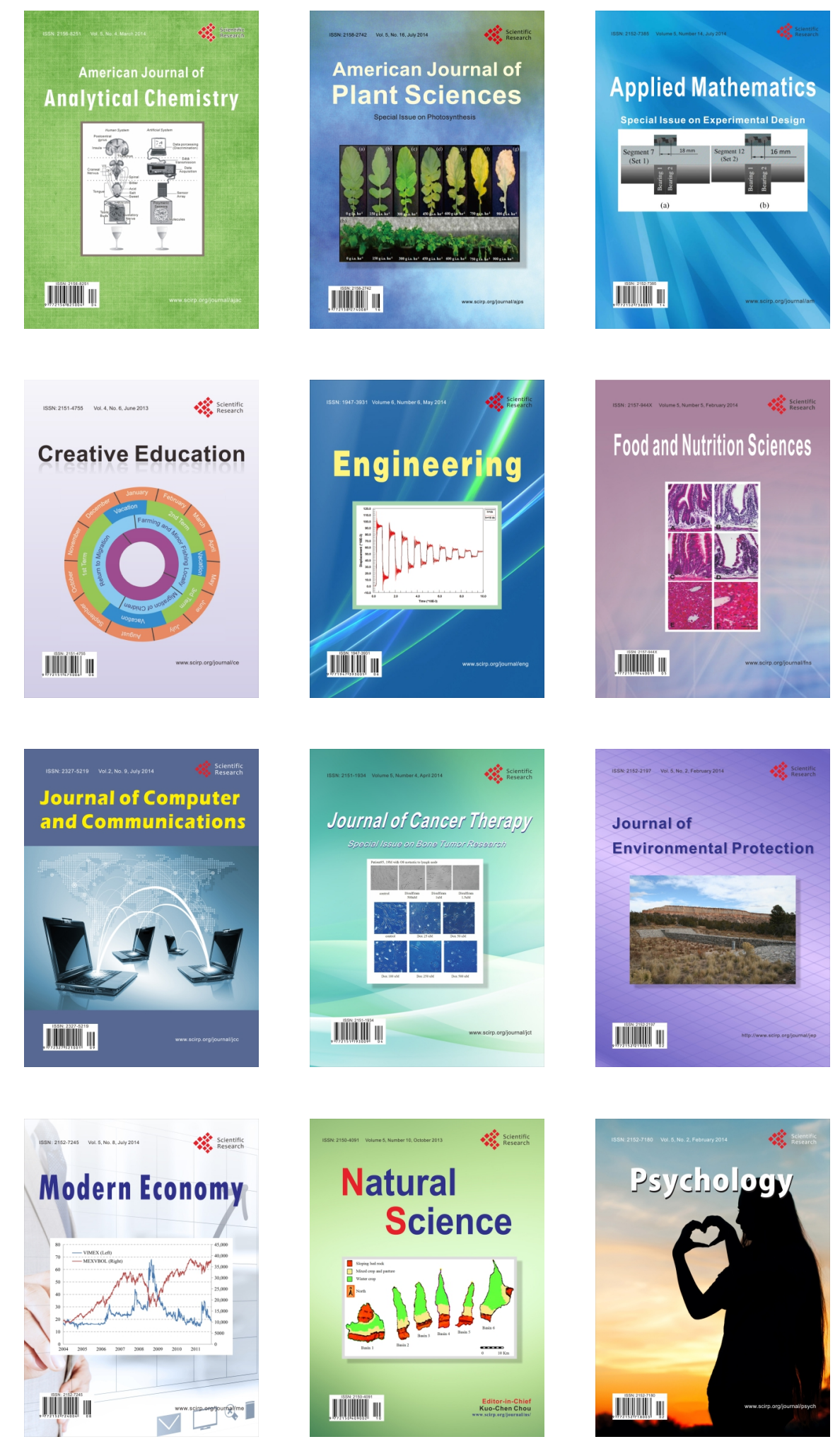